\title{
Pedal Preaxial Polydactyly with Duplication of Talus: A Rare Atypical Presentation
}

\author{
Pasupathy Balasubramanium ${ }^{1}$, Aditya Thakur ${ }^{2}$
}

\begin{abstract}
Introduction: Congenital preaxial polydactyly is usually associated with varus deformity and syndactyly. To our knowledge, this is the first case report of a young child presented with unilateral preaxial polydactyly with two supernumerary rays extending up to accessory talus without varus deformity and syndactyly.

Case description: We present here the case of a 7-year-old girl patient who was presented to us with untreated congenital preaxial polydactyly. A rare case of a young child presented with unilateral preaxial polydactyly with two supernumerary rays extending up to accessory talus without varus deformity and syndactyly. The patient had two extra-toes present on the medial side of her big toe which extended up to talus in her left foot. Surgical excision of complete ray was done.

Conclusion: Surgical acceptance for preaxial polydactyly was quick as it created a barrier for normal walking and difficulty in wearing footwear. Postoperatively, the girl was followed up for 4 years and observed for any problem in varus deformity and foot mechanics.

Keywords: Congenital, Congenital preaxial polydactyl, Congenital, Preaxial polydactyly, Supernumerary rays, Surgical excision, Supernumerary rays.

Journal of Orthopedics and Joint Surgery (2020): 10.5005/jp-journals-10079-1021
\end{abstract}

\section{INTRODUCTION}

Polydactyly is the most common congenital toe deformity, with an incidence of 1.7 per 1,000 live births. A positive family history is present in $30 \%$ of patients. ${ }^{1}$ Preaxial polydactyly is the polydactyly present on the medial side of the foot. The occurrence of preaxial polydactyly is relatively less compared to the postaxial polydactyly. ${ }^{2}$ Few malformations seen along with the preaxial polydactyly are Ellis-van Creveld syndrome, Trisomy 13, tibial hemimelia, and Down syndrome. ${ }^{3}$ On a molecular level, disruptions in the apical ectodermal ridge of the limb bud as a result of abnormalities in Bmp4 have been found to result in both preaxial and postaxial polydactyly. ${ }^{4}$ Treatment involves surgical excision of the extra toes around 1 year of age. Surgery improves cosmesis and facilitates normal shoe fitting. ${ }^{5}$

\section{Case Description}

A 7-year-old girl presented to the outpatient department with difficulty in walking. We found that she had congenital deformity in her left foot, with two extra toes located preaxially. The girl had problems in wearing foot wear. Her right foot was normal.

\section{Examination}

The patient had polydactyly of left foot with two extra toes on the inner aspect of the foot (Fig. 1). Lateral to extra-toes, a normal big toe was present with full muscle power without varus deformity. No vascular and sensory disturbances were found. Right foot had normal five toes. She was the third born child to her mother, with her siblings remaining normal. No history of antenatal, natal, and postnatal complications. She gradually developed difficulty in walking due to hitching of opposite foot during forward propulsion, and it remained a distress for wearing footwear. No family history of congenital anomaly. No respiratory, cardiovascular, and neurological abnormalities were detected (Table 1).

\footnotetext{
1,2Department of Orthopaedics, Madras Medical College, Chennai, Tamil Nadu, India
}

Corresponding Author: Aditya Thakur, Department of Orthopaedics, Madras Medical College, Chennai, Tamil Nadu, India, Phone: +91 9962312660, e-mail: dr.adityathakur@gmail.com

How to cite this article: Balasubramanium P, Thakur A. Pedal Preaxial Polydactyly with Duplication of Talus: A Rare Atypical Presentation. J Orth Joint Surg 2020;2(2):70-73.

Source of support: Nil

Conflict of interest: None

\section{Investigation}

Anteroposterior radiograph (Fig. 2) of left foot showed one accessory talus, one synostosed accessory medial cuneiform, two

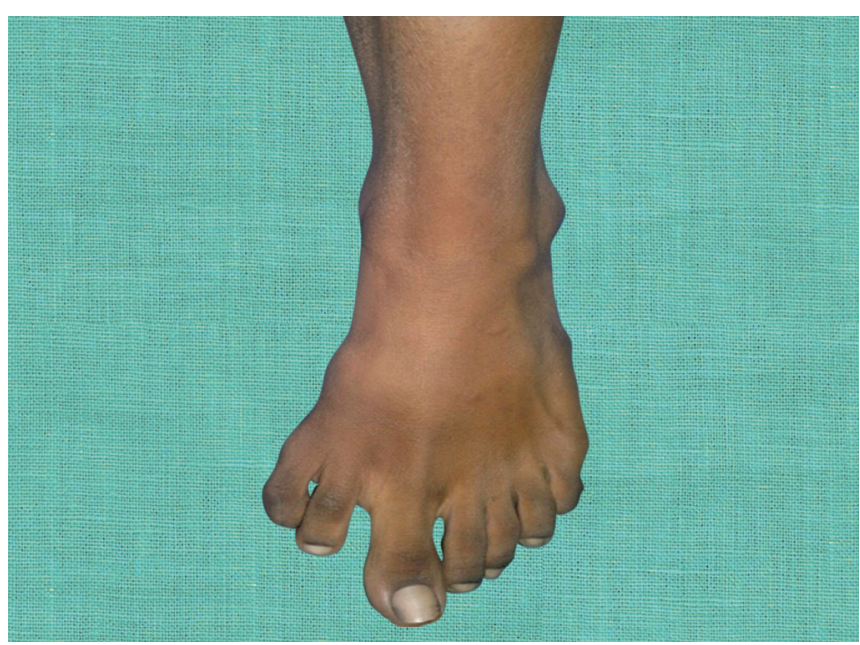

Fig. 1: Preoperative picture of a 7-year-old girl left foot showing preaxial polydactyly 
Table 1: Length of right and left femur, tibia, and limb with differences

\begin{tabular}{lccl}
\hline & Femur $(\mathrm{cm})$ & Tibia $(\mathrm{cm})$ & Limb length $(\mathrm{cm})$ \\
\hline Right side & 38.65 & 35.64 & 74.98 \\
Left side & 40.26 & 30.14 & 71.11 \\
Difference & 1.41 & 5.5 & 3.87 \\
\hline
\end{tabular}

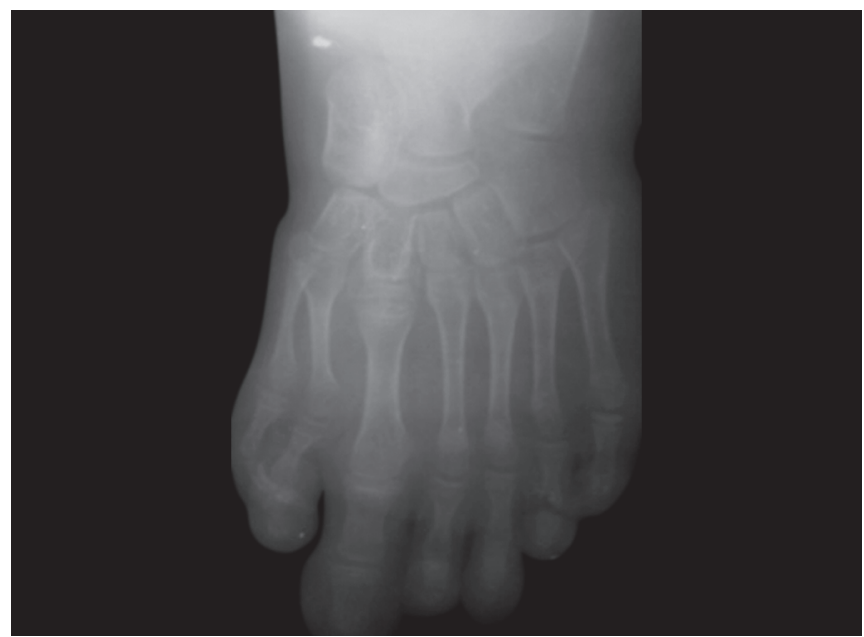

Fig. 2: Anteroposterior radiograph showing 1 accessory talus, 1 synostosed accessory medial cuneiform, 2 accessory metatarsals and 2 accessory proximal phalanges, 2 middle phalanges and 2 distal phalanges placed medially accessory meta tarsals, and two accessory proximal phalanges, two middle phalanges, and two distal phalanges placed medially. In addition (Fig. 3), limb length discrepancy was diagnosed on standing position. To accurate the deformity, anteroposterior radiograph of the entire lower limb was taken. It showed short right femur and short left tibia. Mechanical axis of the limb was drawn, and the segmental length of the femur and tibia was measured bilaterally. Limb length discrepancy on comparison was $3.87 \mathrm{~cm}$. As the discrepancy was greater than $2 \mathrm{~cm}$, temporary epiphysiodesis was advised to patient nearing skeletal maturity.

\section{Management}

The patient was subjected to surgery after 6 months. Our aim was to excise supernumerary rays. Preoperatively basic investigations

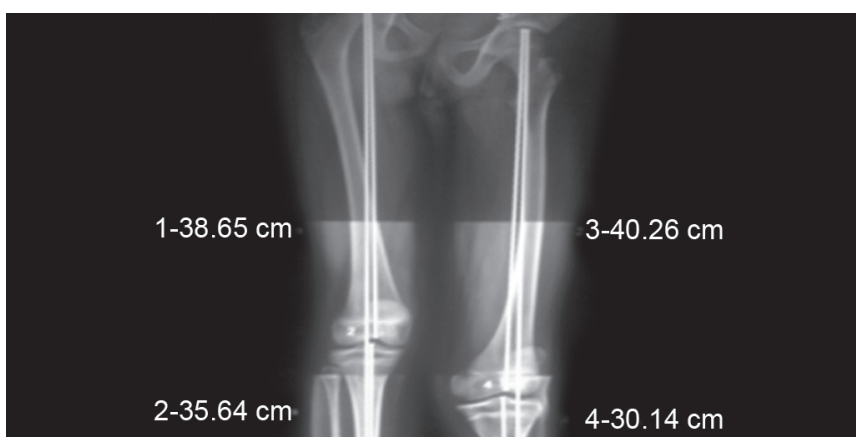

Fig. 3: Anteroposterior radiograph of entire lower limb with mechanical axis line showing short right femur and short left tibia
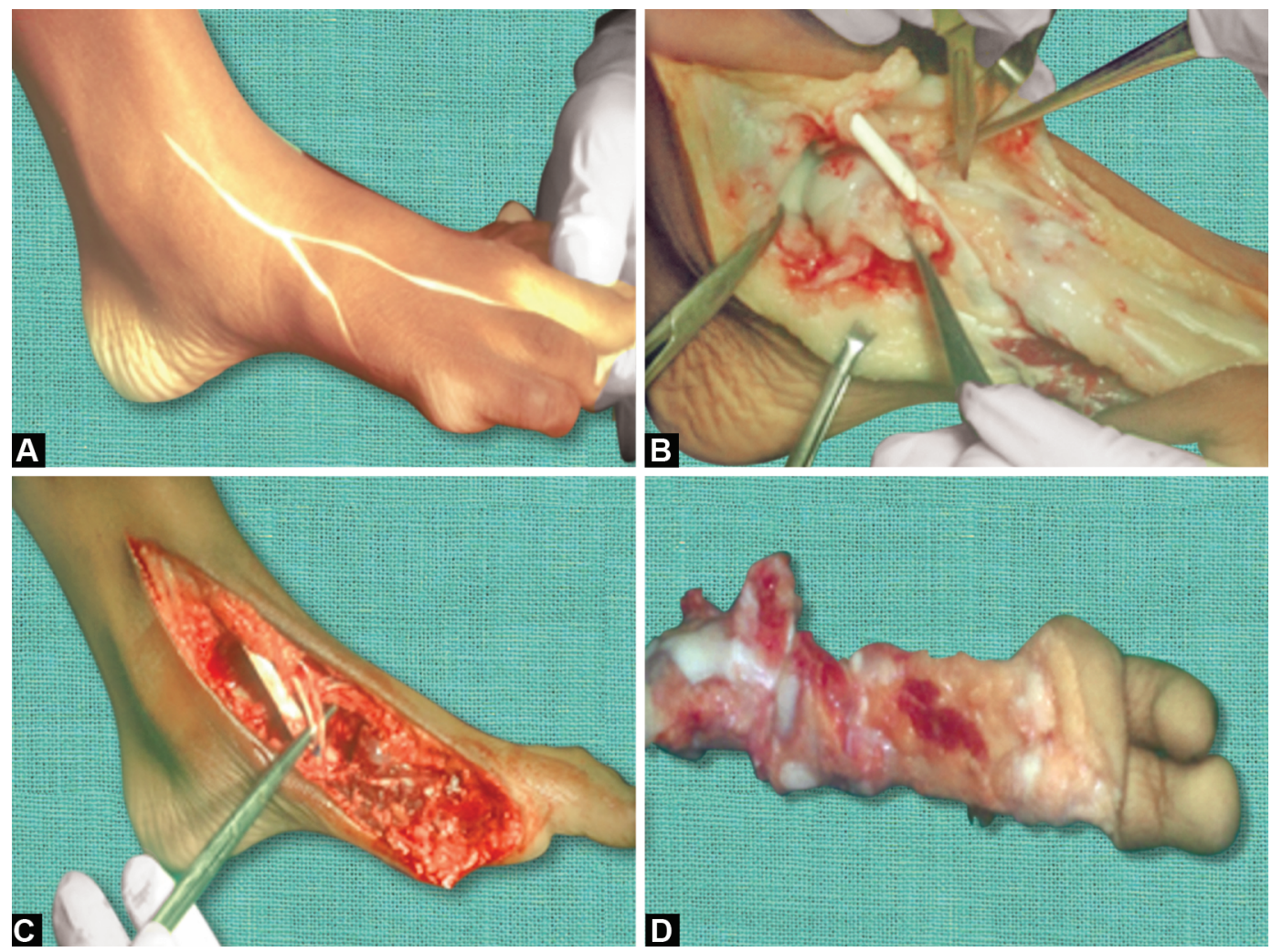

Figs 4A to D: (A) Racquet shaped ray incision was put medial to big toe in left foot extending up to ankle; (B) Intraoperative photograph showing tibialis anterior, abductor hallucis brevis after the excision of supernumerary rays; $(C)$ Intraoperative photograph showing medial neurovascular structures; (D) Postoperative photograph showing excised supernumerary rays 


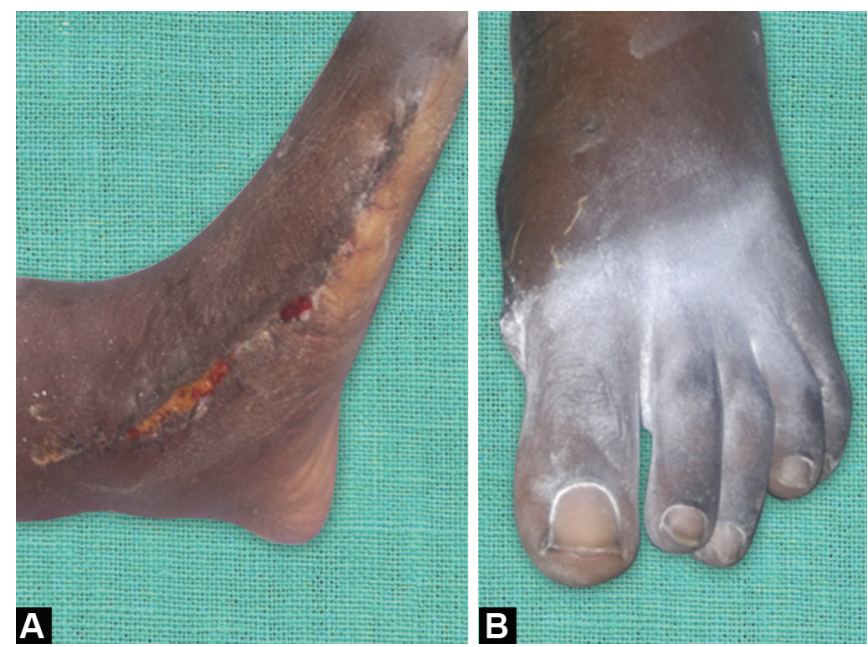

Figs 5A and B: (A) Follow-up after suture removal in 3 weeks; (B) Complete healing after plaster cast removal in 6 weeks

were done and found to be under normal limits. Surgery was performed under general anesthesia. Left foot was painted with betadine solution. Racquet-shaped ray incision was put medial to big toe in the left foot extending up to ankle. Medial neurovascular structures were preserved. Hemostatsis was maintained and the appendages were removed. Care was taken to appropriately balance the abductor hallucis and tibialis anterior muscles. The soft tissue and skin were repaired as accurately as possible. The medial border was closed by 2-0 ethilon sutures (Fig. 4).

\section{Outcome}

Postoperatively, below-knee plaster cast was put for 4-6 weeks to maintain the position and to avoid varus deformity. After adequate healing, sutures were removed on day 14 . As the surgery was a simple procedure, the functional outcome was satisfactory (Fig. 5). Recovery was hastened by ankle foot orthoses. It helped in the formation of medial arch of foot and early mobilization. The patient was monitored and followed up for 4 years. The girl is now able to walk without any difficulty (Fig. 6).

\section{Discussion}

Adam et al. observed clinical findings in 18 cases of diabetic embryopathy and preaxial halluxal polydactyly to identify the features most suggestive of diabetic embryopathy. Other findings included spinal segmentation anomalies, equinovarus deformity of the feet, tibial hemimelia, hip dysplasia, and femoral hypoplasia. The authors found that preaxial halluxal polydactyly, particularly when coupled with anomalies of the spine and tibial hemimelia, is highly suggestive of diabetic embryopathy. ${ }^{6}$ Akin and Ozcan described a 14-month-old boy with nonclassified preaxial polydactyly of foot with triplication of the first metatarsal (three separate big toes) associated with hand anomalies and short tibia.?

Our case was unique as it did not come under standard Watanabe classification. ${ }^{8}$ The surgical management is commonly performed for cosmetic, footwear, and psychological reasons. The preoperative radiographs should be obtained to define the anatomy of the metatarsal. In few cases, skin graft and wedge osteotomy are performed to correct the axis deviation. For limb length discrepancies greater than $2 \mathrm{~cm}$ but less than $5 \mathrm{~cm}$, in growing children, epiphysiodesis is done. This means surgically
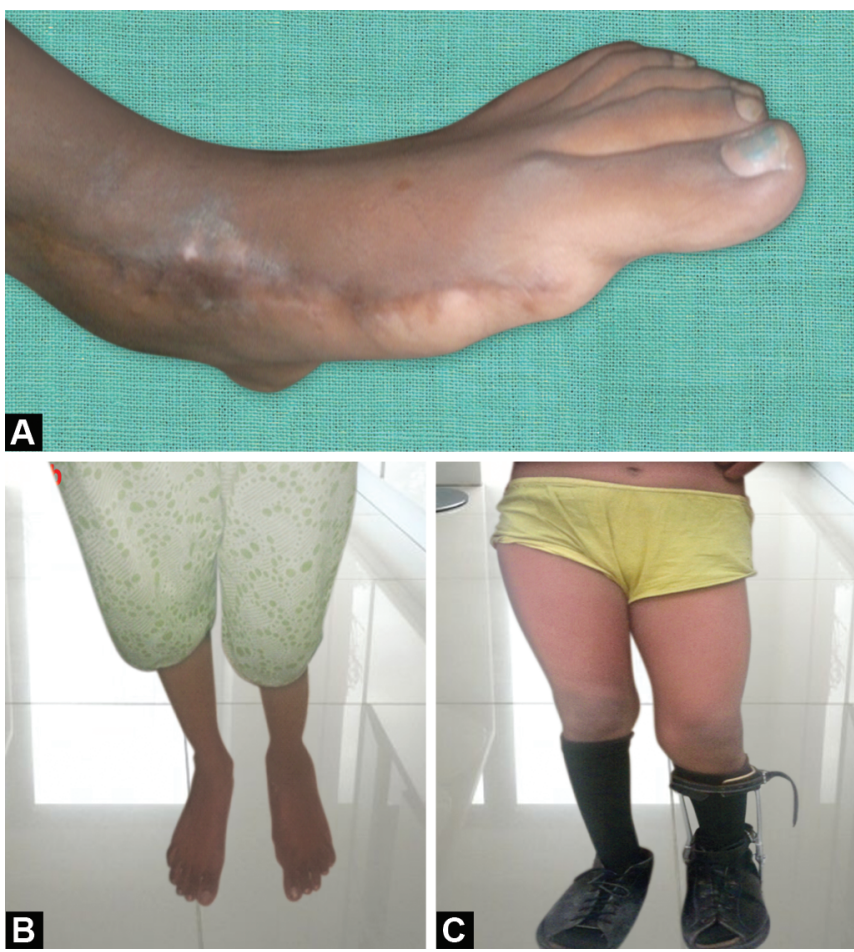

Figs 6A to C: (A) Follow-up after 1 year; (B) Follow-up after 3 years; (C) Follow-up with ankle foot orthosis

closing one or more growth plates. Children have one growth plate at each end of the femur and tibia and fibula. It slows down the growth of the long leg by a predictable amount, allowing the short leg to catch up. If this procedure is performed too early or too late for age, too much or too little correction, respectively, will result. For patients who do not want to undergo epiphysiodesis for discrepancies less than $5 \mathrm{~cm}$, limb lengthening is the procedure of choice to achieve leg length equalization.

\section{Conclusion}

Excision is highly performed for foot rather than for hand due to superstitious belief. Poor glycemic control in the diabetic mothers and genetic predisposition lead to specific limb anomalies. So ante natal mothers have to be investigated for diabetes and given treatment once identified. Our case is rare as there was no history of gestational diabetes in the mother, no hereditary predisposition, unilateral presentation, no varus deformity, no spinal anomalies, and no associated syndromes. The proximally placed preaxial extra toes extending up to talus bone is a very rare type. Early detection and adequate excision of the longitudinal bracket affecting the metatarsal will help to reduce the functional deformity.

\section{References}

1. Phelps DA, Grogan DP. Polydactyly of the foot. J Pediatr Orthop 1985;5(4):446-451. DOI: 10.1097/01241398-198507000-00012.

2. Belthur MV, Linton JL, Barnes DA. The spectrum of preaxial polydactyly of the foot. J Pediatr Orthop 2011;31(4):435-447. DOI: 10.1097/BPO.0b013e3182199a68.

3. Castilla EE, Lugarinho R, Dutra $M$, et al. Associated anomalies in individuals with polydactyly. Am J Med Genet 1998;80(5):459-465. DOI: 10.1002/(sici)1096-8628(19981228)80:53.0.co;2-g. 
4. Selever J, Liu W, Lu MF, et al. Bmp4 in limb bud mesoderm regulates digit pattern by controlling AER development. Dev Biol 2004;276(2):268-279. DOI: 10.1016/j.ydbio.2004.08.024.

5. Galois L, Mainard D, Delagoutte JP. Polydactyly of the foot literature review and case presentations. Acta Orthop Belg 2002;68(4): 376-380.
6. Novick C, Grogan DP. Polydactyly of the foot. J Med Genet 1999;36: 33-40.

7. Akin S, Ozcan M. A non classified preaxial polydactyly of foot. Europ J Plast Surg 1997;20(3):161-163. DOI: 10.1007/BF01002054.

8. Chang T-C, Hsiao H-T, Tu LC, et al. Surgical treatment for polydactyly of foot. JTSPS 2011;20(3):167-177. 